\title{
The rhizosphere effect on soil gross nitrogen mineralization: A meta-analysis
}

\author{
Dayong Gan ${ }^{1,2}$, Hui Zeng ${ }^{2}$, Biao Zhu ${ }^{1, *}$ \\ 1 Institute of Ecology, College of Urban and Environmental Sciences, and Key Laboratory for Earth Surface Processes of the Ministry of \\ Education, Peking University, Beijing 100871, China \\ 2 School of Urban Planning and Design, Shenzhen Graduate School, Peking University, Shenzhen 518055, China
}

\section{H I G H L I G H T S}

- We performed a meta-analysis to synthesize the rhizosphere effect on soil gross nitrogen mineralization rate.

- It was $81 \%$ on average, being significantly higher in woody (than non-woody species) and in ECM associated species (than AM associated species).

- It was positively correlated with the rhizosphere effects on soil $\mathrm{C}$ mineralization rate, microbial biomass nitrogen, phenol oxidase activity and root biomass.

- Its variations were mainly controlled by soil microbial variables and plant factors rather than climatic factors.

\section{ARTICLE INFO}

Article history:

Received February 5, 2021

Revised April 9, 2021

Accepted April 29, 2021

Keywords:

Rhizosphere effect

Carbon mineralization

Nitrogen mineralization

Microbial biomass

Mycorrhizal association

Plant-soil interaction
GRAPHICAL ABSTRACT
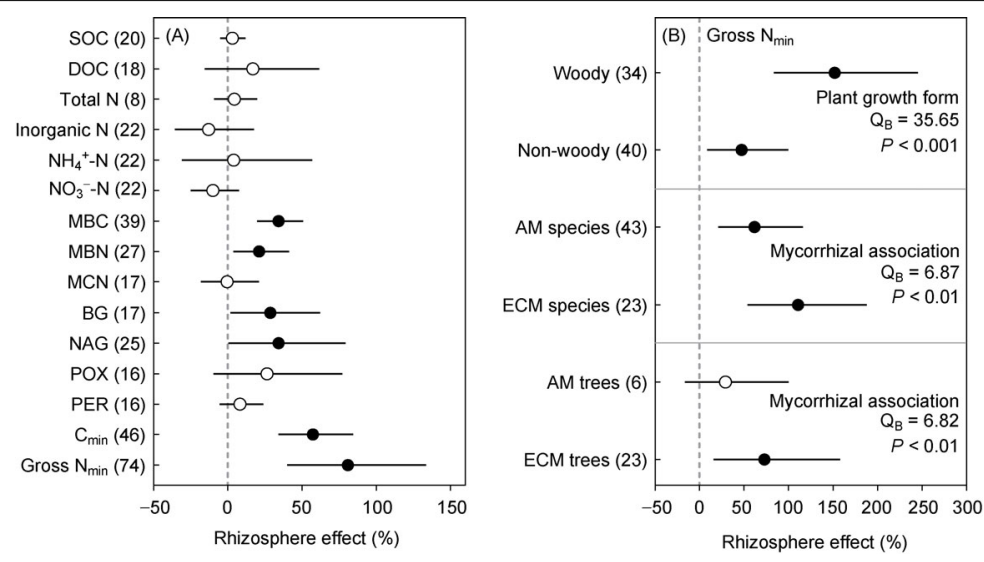

A B S T R A C T

Rhizosphere effects play crucial roles in determining soil carbon (C) and nitrogen (N) cycling. However, the rhizosphere effect on soil gross nitrogen $(N)$ mineralization $\left(N_{\min }\right)$ has not been quantitatively assessed on the global scale. Here we performed a meta-analysis of compiled data from 24 publications and 37 species to synthesize the rhizosphere effect on soil gross $N_{\min }$ and its influencing factors. We found that the rhizosphere effect significantly enhanced soil gross $N_{\min }$ by $81 \%$ on average. Such rhizosphere effect was significantly higher in woody species than in nonwoody species, and higher in ECM (ectomycorrhizal) associated species than in AM (arbuscular mycorrhizal) associated species. Moreover, the variations of the rhizosphere effect on soil gross $\mathrm{N}_{\min }$ were correlated with those on soil $\mathrm{C}$ mineralization, phenol oxidase activity and root biomass rather than with other plant (growth form and mycorrhizal association) and climatic (mean annual temperature and precipitation) factors. These results support the 'microbial activation' and 'microbial $\mathrm{N}$ mining' hypotheses of rhizosphere effects and indicate the coupling of soil $\mathrm{C}$ and gross $\mathrm{N}$ mineralization in the rhizosphere. Overall, these findings provide novel insights into the rhizosphere effect on soil gross $\mathrm{N}_{\min }$ among plant growth forms and mycorrhizal associations, and improve our mechanistic understanding of soil $\mathrm{N}$ dynamics in the rhizosphere.

(c) Higher Education Press 2021

\footnotetext{
* Corresponding author

E-mail address: biaozhu@pku.edu.cn (B. Zhu)
} 


\section{Introduction}

It has been widely known that plant roots greatly affect soil carbon (C) and nutrient cycling in the rhizosphere through plant-soil interactions (Koranda et al., 2011; Kuzyakov and $\mathrm{Xu}, 2013$; Cheng et al., 2014). The intense rhizosphere processes make a difference in physical, chemical or biological properties between rhizosphere soils and root-free bulk soils, which are described as rhizosphere effects (Phillips and Fahey, 2006; Finzi et al., 2015). Such effects are normally assessed via the comparison of soil organic matter (SOM) decomposition rate in the presence or absence of living roots (Cheng and Kuzyakov, 2005; Kuzyakov, 2010; Dijkstra et al., 2021), which is termed rhizosphere priming effect (RPE) (Kuzyakov, 2002; Cheng et al., 2014). Nitrogen (N) is widely regarded as the key limiting nutrient for plant growth in terrestrial ecosystems (Lebauer and Treseder, 2008; Frank and Groffman, 2009; Li et al., 2021), and soil N cycling is complicated, involving many simultaneously occurring transformation processes (Holz et al., 2016). Given the method challenges in measuring soil gross $\mathrm{N}$ mineralization rate $\left(\mathrm{N}_{\text {min }}\right)$ (Murphy et al., 2003), there is much less attention about rhizosphere effects on soil gross $\mathrm{N}_{\text {min }}$ compared to those on soil $C$ mineralization rate $\left(C_{\min }\right)$ (Kuzyakov, 2002; Booth et al., 2005; Zhu et al., 2014; Yin et al., 2018; Sun et al., 2021).

A recent meta-analysis assessed the direction and magnitude of rhizosphere effects on soil gross $\mathrm{N}_{\min }$ and other indices of $\mathrm{C}$ and $\mathrm{N}$ cycling mediated by microbes (Finzi et al., 2015). It showed that rhizosphere processes could accelerate soil $\mathrm{N}$ mineralization, and thus the rhizosphere effect on soil gross $N_{\min }$ was significantly positive in all ecosystems. However, the sample size of soil gross $\mathrm{N}_{\min }$ was small $(n=11)$ and woody species $(n=8)$ dominated the database in that study (Finzi et al., 2015). Hence, a comprehensive and updated meta-analysis is urgently needed to consider the general patterns of rhizosphere effects on soil gross $N_{\min }$ by including a larger number of species and more sufficient study cases.

Several mechanisms of RPEs have been proposed, while the rhizosphere effect on soil $\mathrm{N}$ mineralization remains poorly understood (Kuzyakov, 2010; Cheng et al., 2014; Yin et al., 2018). Generally, microbial physiology would change under distinct $\mathrm{C}$-limited or $\mathrm{N}$-limited conditions, thereby affecting SOM decomposition and $\mathrm{N}$ mineralization (Mo et al., 2021). The 'microbial $\mathrm{N}$ mining' hypothesis postulates that microbial enzyme production would increase to promote the availability of $\mathrm{N}$ released from SOM under nutrient-limited conditions (Craine et al., 2007; Fontaine et al., 2011). By contrast, the 'microbial activation' hypothesis states that root exudates act as a source of substrates for microbes, stimulate the growth of microbes to secrete more enzymes, and enhance the decomposition of SOM (Kuzyakov, 2002; Zhu et al., 2014). These two hypotheses could explain positive RPEs, while negative RPEs may be explained by the hypothesis of 'preferential substrate utilization' (Cheng, 1999; Dijkstra et al., 2013). It demonstrates that the demand of microbes for nutrients is reduced when soil mineral $\mathrm{N}$ is rich. Microbes thereby prefer to utilize root exudates instead of recalcitrant SOM decomposition. Collectively, soil nutrient availability and microbes play an important role in the direction and magnitude of RPEs. Moreover, some case studies revealed a positive linear relationship between primed $\mathrm{C}_{\text {min }}$ and primed gross $\mathrm{N}_{\min }$ (Dijkstra et al., 2009; Yin et al., 2018), indicating the coupled nature of $\mathrm{C}$ and $\mathrm{N}$ mineralization. Similarly, the relationships between rhizosphere effect on soil gross $N_{\text {min }}$ and that on soil and microbial variables (e.g., $\mathrm{N}$ availability, microbial biomass and enzyme activity) need further investigation.

In addition to soil factors (e.g., soil $\mathrm{C}$ and $\mathrm{N}$ availability), plant species and mycorrhizal associations could affect soil $\mathrm{C}$ and $\mathrm{N}$ cycling via rhizosphere effects (Cheng et al., 2003; Phillips and Fahey, 2006; Sun et al., 2014). Specifically, plant species own specific adaptive traits for resource acquisition and conservation, and participate in soil nutrient cycling (Hobbie, 1992; Maire et al., 2015). Hamer and Makeschin (2009) stated that plant species may alter rhizospheric microbial community composition, indirectly influencing soil $\mathrm{N}$ mineralization (Henneron et al., 2020). Moreover, mycorrhizal association has been increasingly recognized as an important root biotic trait for soil carbon and nutrient cycling (Colin-Belgrand et al., 2003; Weemstra et al., 2016). Plant species mainly associate with arbuscular mycorrhizal fungi (AM-associated species or AM species hereafter) or ectomycorrhizal fungi (ECM-associated species or ECM species hereafter). These two types of plants have distinct $N$ acquisition strategies (Read and Perez-Moreno, 2003; Brzostek et al., 2013; Yin et al., 2014), possibly causing the difference in the magnitude and direction of rhizosphere effects. A previous study reported that ECM trees exhibit greater rhizosphere effects on net $\mathrm{N}_{\min }$ compared to $\mathrm{AM}$ trees (Phillips and Fahey, 2006). However, two recent studies (Chen et al., 2018b; Han et al., 2020a) found that rhizosphere effects on $\mathrm{C}_{\text {min }}$ and net $\mathrm{N}_{\text {min }}$ did not vary significantly between AM and ECM mycorrhizal groups in temperate forests. Therefore, a further comparison of rhizosphere effects among plant growth forms (woody species and non-woody species) and particularly mycorrhizal associations with more sufficient data should be performed. Furthermore, plant biomass and root morphology may directly or indirectly affect soil carbon-nutrient cycling (Han et al., 2020a; Sun et al., 2021). Some studies showed a positive link between plant biomass and RPE across different plant species (Dijkstra and Cheng, 2007; Huo et al., 2017; Yin et al., 2018). However, whether this correlation exists between the rhizosphere effect on gross $\mathrm{N}_{\min }$ and plant biomass remains unknown.

Here we conducted a meta-analysis to assess the rhizosphere effect on soil gross $\mathrm{N}_{\text {min }}$ under different plant growth forms and mycorrhizal associations. Specifically, the aims of this study were to: (i) quantify the direction and magnitude of the rhizosphere effect on soil gross $\mathrm{N}_{\min }$ across and within plant growth forms and mycorrhizal associations; and 
(ii) investigate how the rhizosphere effects on soil $C$ and nutrient contents, microbial biomass and enzyme activities correlate with the rhizosphere effect on soil gross $\mathrm{N}_{\min }$ across and within plant growth forms, mycorrhizal associations and plant biomass; and (iii) evaluate how soil, plant and climatic factors jointly influence the rhizosphere effect on soil gross $N_{\text {min }}$. We tested two specific hypotheses: 1) soil gross $N_{\text {min }}$ would be accelerated due to rhizosphere effects and such effects would differ among plant growth forms and mycorrhizal associations; and 2) the rhizosphere effect on soil gross $\mathrm{N}_{\min }$ would significantly correlate with the rhizosphere effects on soil microbial variables and plant factors which explain a larger proportion of the variations of the rhizosphere effect on soil gross $\mathrm{N}_{\min }$ than climatic factors.

\section{Materials and methods}

\subsection{Data collection}

Data were collected from peer-reviewed journal articles, up to
March 1st, 2021. In this meta-analysis, we searched on the Web of Science (ISI) and China National Knowledge Infrastructure $(\mathrm{CNKI})$, using the search terms (rhizosphere effect* OR rhizosphere soil) AND (soil gross nitrogen mineral* ${ }^{*}$ R soil nitrogen flux* OR soil nitrogen cycling ${ }^{*}$ ). Four criteria were implemented to screen appropriate articles. (a) Gross nitrogen mineralization rate measured by the ${ }^{15} \mathrm{~N}$ pool dilution method was reported. (b) The rhizosphere effects were directly reported, or paired rhizosphere and bulk soils were reported simultaneously at species level. Notably, some studies included treatments with and without roots, which were regarded as rhizosphere and bulk soils, respectively. (c) The means, standard deviations (SDs) or standard errors (SEs), and sample sizes of the target variables were reported in texts, tables or figures. Finally, 24 published articles were selected from 1243 references (Fig. 1).

We extracted the sample sizes, means and SDs (or SEs) of soil gross $\mathrm{N}_{\min }$ in both rhizosphere and bulk soils. Moreover, some important variables such as soil chemical properties (soil organic $\mathrm{C}$ [SOC], dissolved organic $\mathrm{C}$ [DOC], total $\mathrm{N}$, soil $\mathrm{NH}_{4}{ }^{+}-$ $\mathrm{N}$, soil $\mathrm{NO}_{3}{ }^{-}-\mathrm{N}$ ), microbial biomass (microbial biomass $\mathrm{C}$ [MBC],
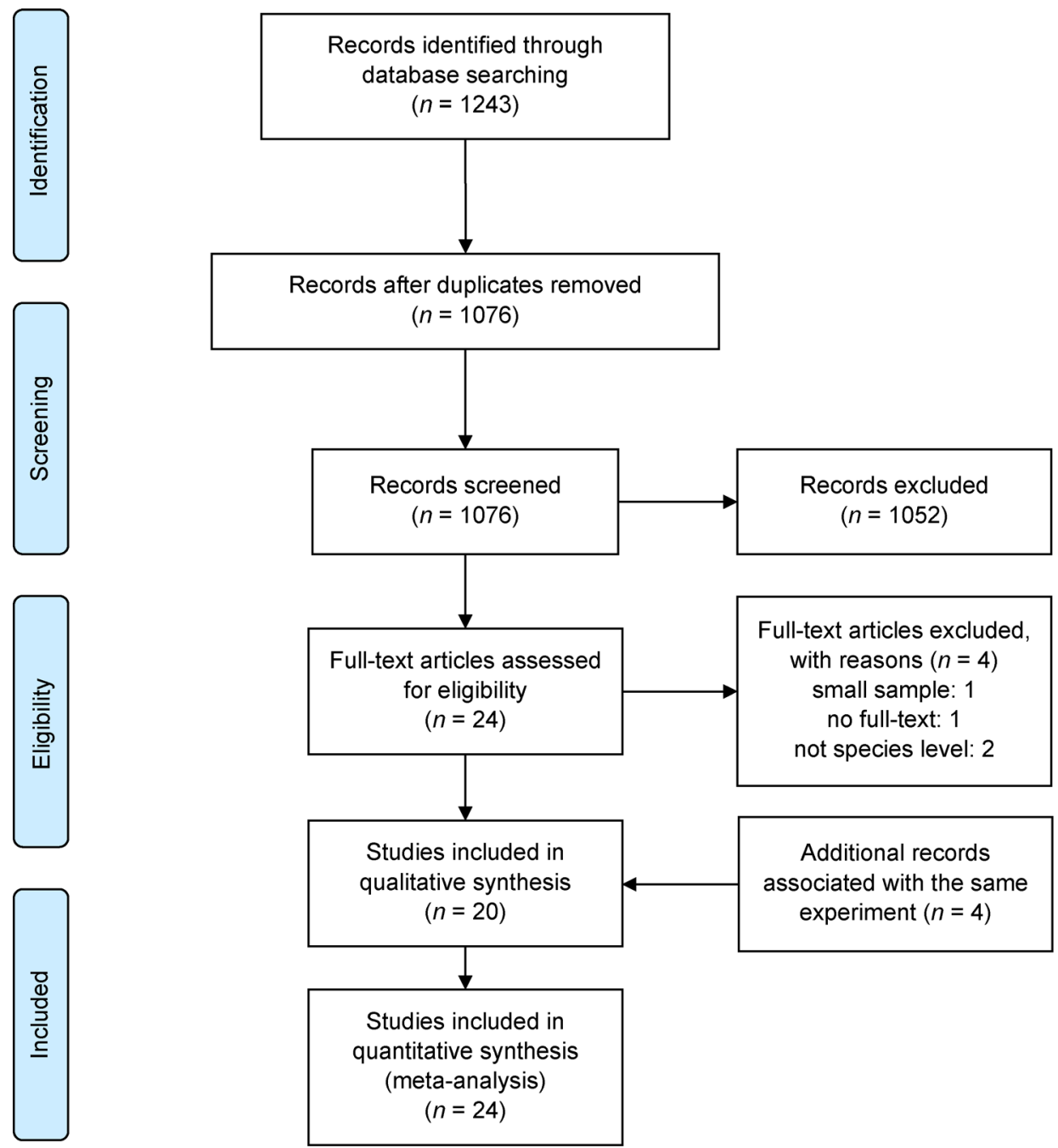

Fig. 1 Meta-analysis flow diagram. 
microbial biomass $N$ [MBN]), enzyme activities ( $\beta$-1,4-glucosidase $[B G], \beta-1,4-N$-acetyl-glucosaminidase [NAG], phenol oxidase [POX] and peroxidase [PER]) and $C_{\min }$ were collected. Most of the data would be directly attainable, and some in figures were obtained by the software GetData (version 2.25). In addition to these target variables, we also recorded the site information (latitude, longitude, mean annual temperature (MAT), mean annual precipitation (MAP)) and experiment information (experimental types, rhizosphere soil sampling methods; Table S1). The site information was obtained as much as possible from the original articles or relevant studies, otherwise they were searched from the climatic database at https://power.larc.nasa.gov/data-access-viewer/. For each species, plant growth forms were categorized as woody and nonwoody. Mycorrhizal types were mainly categorized into arbuscular mycorrhizal (AM) and ectomycorrhizal (ECM), which were confirmed according to Wang and Qiu (2006) and Soudzilovskaia et al. (2020). In case the mycorrhizal type of the species was not available, it was categorized according to the mycorrhizal type of other species in the same genus (Keller and Phillips, 2019; Soudzilovskaia et al., 2020). Notably, we regarded plant species having both $\mathrm{AM}$ and ECM fungal associations or unknown fungal associations as "others" (Table S2). We also collected other plant variables, including plant root biomass, shoot biomass and total biomass. Moreover, experiment types were divided into field (e.g., Meier et al., 2015) and pot/greenhouse (e.g., Zhu et al., 2014) in terms of experiment settings. The inconsistent sampling methods for rhizosphere soil may confound the real differences in rhizosphere effects within and among species. A previous study comparing different methods to measure rhizosphere effect showed that the rootshaking method generated stronger rhizosphere effects compared with the root-chamber method (Ding et al., 2019). Therefore, we divided soil sampling methods (rhizosphere and bulk soil separation method) into shaking (e.g., Phillips and Fahey, 2006) and other methods (others), according to the description of each study. The other methods include rhizobox (e.g., Pokharel et al., 2021) and distance measurement (e.g., Herman et al., 2006). In total, 37 species and 390 observations from 23 study sites were included in this meta-analysis. The distribution of study sites was created by the software ArcGIS (version 10.2.2) and presented in Fig. S1.

\subsection{Statistical analysis}

To indicate the rhizosphere effects on soil gross $N_{\min }$ and other variables, we used the natural log of the response ratio $(R R)$ as an effect size (Hedges et al., 1999; Luo et al., 2006):

$$
R R=\ln \left(\frac{\overline{X_{R}}}{\overline{X_{B}}}\right)=\ln \left(\overline{X_{R}}\right)-\ln \left(\overline{X_{B}}\right)
$$

where $\overline{X_{R}}$ and $\overline{X_{B}}$ are the mean values of a specific variable in rhizosphere soil and bulk soil, respectively. The corresponding pooled variance $(v)$ was calculated as follows:

$$
v=\frac{S_{R}^{2}}{n_{R}{\overline{X_{R}}}^{2}}+\frac{S_{B}{ }^{2}}{n_{B}{\overline{X_{B}}}^{2}}
$$

where $n_{R}$ and $n_{B}$ are the sample sizes; and $S_{R}$ and $S_{B}$ are the standard deviations of means in rhizosphere soil and bulk soil groups, respectively. For 3 studies that did not report SDs or SEs, we approximately assigned the SDs as the means of all other SDs (Bai et al., 2013; Feng and Zhu, 2019). Values of $R R>0$ indicate positive rhizosphere effects, while values of $R R<0$ indicate negative rhizosphere effects.

In some experiments, when data points were repeatedly measured at different times under the same treatment, they were aggregated by the following equations (Liao et al., 2008; Huo et al., 2017):

$$
\begin{gathered}
M=\sum_{i=1}^{j} \frac{M_{i}}{j} \\
S D=\sqrt{\frac{\sum_{i=1}^{j} S D_{i}^{2}\left(n_{i}-1\right) n_{i}}{\left(\sum_{i=1}^{j} n_{i}-1\right) \Sigma_{i=1}^{j} n_{i}}}
\end{gathered}
$$

where $M$ is the overall aggregated mean and $S D$ is the associated standard deviation under the particular treatment; $j$ is the number of repeated measurement $(j \geqslant 2), M_{i}, S D_{i}$ and $n_{i}$ are the mean, standard deviation and sample size on the ith sampling time, respectively. After the removal of timedependency, the pooled data points of soil gross $\mathrm{N}_{\min }$ for rhizosphere soil and bulk soil groups were reduced from 86 to 74.

The weighted response ratio $\left(R R_{++}\right)$and its corresponding $95 \%$ confidence intervals (Cls) were calculated using the rma.mv function in the 'metafor' package on mixed-effects model (Viechtbauer, 2010). For some case studies consisting of multiple experiment sites that may contribute more than one effect size, the variable "site" was set as a random factor in the model (Chen et al., 2018a; Feng and Zhu, 2021). The rhizosphere effect on a given variable was considered to be significant $(P<0.05)$ if the $95 \% \mathrm{Cls}$ of $R R_{++}$did not overlap zero. To test whether rhizosphere effects differed in plant and mycorrhizal groups, the between-group heterogeneity $\left(Q_{\mathrm{B}}\right)$ test was performed. A significant $Q_{\mathrm{B}}$ indicates the rhizosphere effect shows significant differences among groups (Liu et al., 2016). For a better interpretation, the $R R_{++}$and its $95 \% \mathrm{Cls}$ were transformed to the percentage change $(\%)$ by the following formula: $\left(\exp \left(R R_{++}\right)-1\right) \times 100 \%$. Such percentage change is equal to the rhizosphere effect (\%) calculated by the relative change of a variable between paired rhizosphere and bulk soils ([rhizosphere - bulk]/bulk). Moreover, the publication bias was tested using Kendall's tau rank correlation and Spearman's rank correlation between individual response ratios and their corresponding variance of each variable (Dieleman and Janssens, 2011).

We first conducted the Pearson correlation analysis to explore the relationships between the rhizosphere effect on soil gross $N_{\min }$ with bulk soil properties and rhizosphere effects on other biogeochemical variables. We also performed the simple linear regression analysis to examine the specific 
relationships between the rhizosphere effect on soil gross $\mathrm{N}_{\text {min }}$ and certain soil variables (DOC, MBN, POX and $\mathrm{C}_{\min }$ ), plant variables (root biomass, shoot biomass and total biomass) and climatic variables (MAT and MAP), using the original value instead of aggregated value. Furthermore, a weighted random-forest analysis was carried out to identify the relative importance of the variables that influenced the rhizosphere effect on soil gross $\mathrm{N}_{\text {min }}$, including soil continuous variables (e.g., rhizosphere effects on soil properties and microbial activities), plant variables (e.g., plant growth forms, mycorrhizal associations and root biomass) and climatic variables (MAT and MAP) (Jiao et al., 2018; Terrer et al., 2019; Han et al., 2020b). The importance of a variable was expressed as the increase in the mean square error (\%IncMSE) and higher MSE\% values implied more important predictors. All statistical analyses were performed using the $\mathrm{R}$ platform (version 3.6.2).

\section{Results}

\subsection{Rhizosphere effects on soil gross $\mathrm{N}_{\min }$}

Across all studies, soil gross $\mathrm{N}_{\text {min }}$ was significantly enhanced in rhizosphere soil compared to bulk soil, and the overall average rhizosphere effect was $81 \%$ with the $95 \% \mathrm{Cls}$ from
$40 \%$ to $134 \%$ ( $n=68$; Fig. 2). In addition, the rhizosphere effects on variables of soil biogeochemical processes were mostly positive, being significant for microbial biomass $\mathrm{C}$ (34\%), microbial biomass $N(21 \%), \beta-1,4$-glucosidase $(29 \%)$, $\beta-1,4-N$-acetyl-glucosaminidase $(34 \%)$ and $C_{\min }(57 \%)$. However, the rhizosphere effects on other variables were nonsignificant (Fig. 2A).

There were significant differences in the rhizosphere effect on soil gross $\mathrm{N}_{\text {min }}$ among plant growth forms and mycorrhizal associations (Fig. 2B). The rhizosphere effect on soil gross $\mathrm{N}_{\text {min }}$ was larger in woody species (152\%) compared to nonwoody species $(47 \%)$, and it was larger in ECM species $(111 \%)$ than in AM species (62\%). Similarly, ECM trees exhibited a stronger rhizosphere effect on soil gross $\mathrm{N}_{\min }$ compared with AM trees $(73 \%$ vs. $29 \%)$. In contrast, the rhizosphere effect on soil gross $\mathrm{N}_{\text {min }}$ did not vary with experimental types and soil sampling methods (Fig. S2). Notably, there was no significant publication bias for the rhizosphere effects on all variables (Table S3).

\subsection{Factors influencing the rhizosphere effect on soil gross $\mathrm{N}_{\text {min }}$}

Correlation analysis showed that the rhizosphere effect on soil gross $\mathrm{N}_{\min }$ had no significant correlation with the rhizosphere
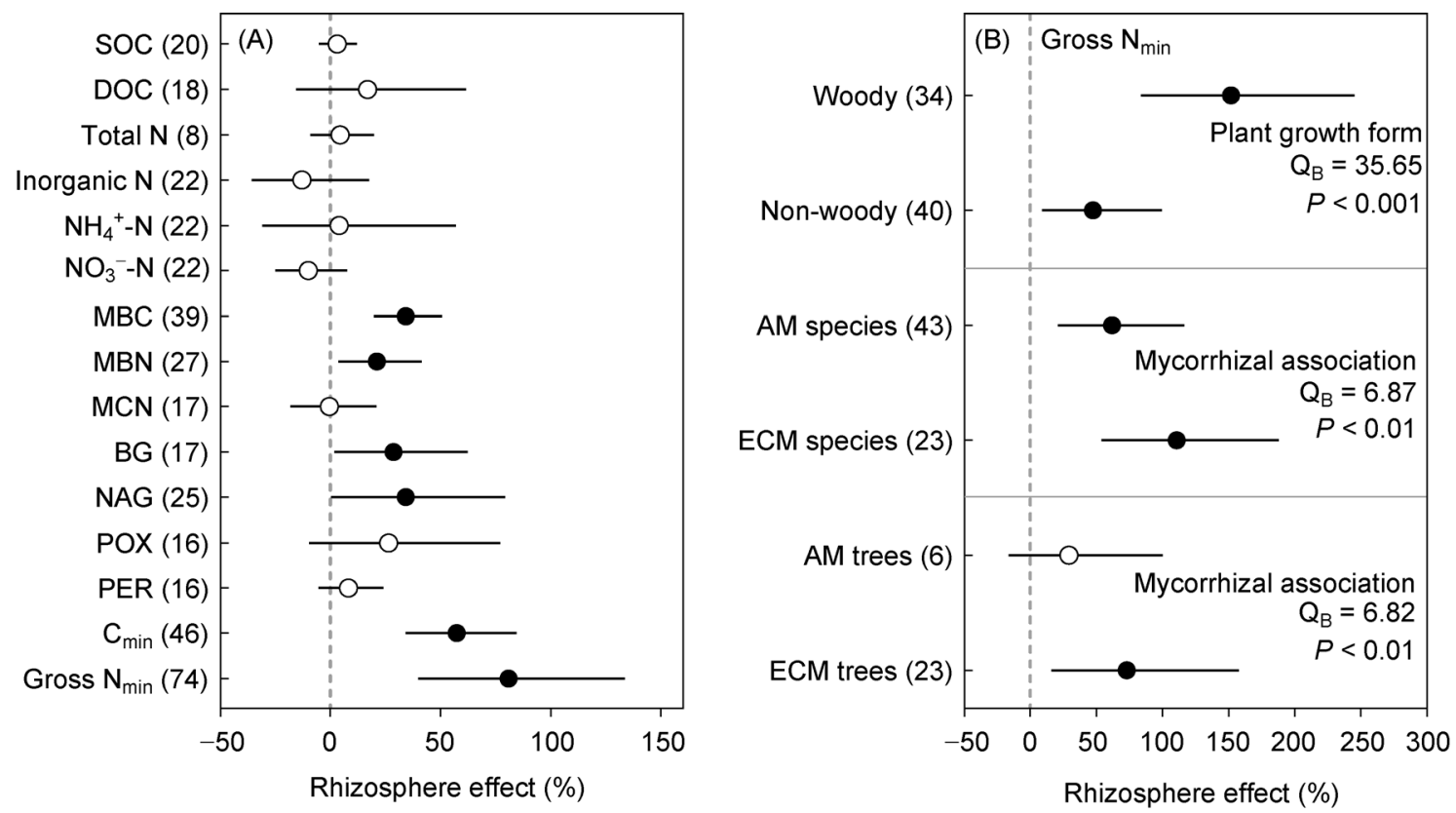

Fig. 2 Rhizosphere effects (\%) on soil variables and biogeochemical processes. Rhizosphere effects (\%) are calculated as the percentage change transformed by weighted response ratio, which is similar to the relative change between rhizosphere and bulk soils ([rhizosphere bulk]/bulk). SOC: soil organic carbon (C), DOC: dissolve organic $\mathrm{C}, \mathrm{NH}_{4}{ }^{+}-\mathrm{N}$ : ammonium nitrogen (N), $\mathrm{NO}_{3}{ }^{-} \mathrm{N}$ : nitrate $\mathrm{N}, \mathrm{MBC}^{-}$microbial biomass $C$, MBN: microbial biomass $N$, BG: $\beta-1,4$-glucosidase, NAG: $\beta-1,4-N$-acetyl-glucosaminidase, POX: phenol oxidase, PER: peroxidase, $C_{\min }: C$ mineralization rate, $\mathrm{N}_{\min }: \mathrm{N}$ mineralization rate. The numbers in parentheses indicate sample sizes of observations. Plant growth forms represent woody and non-woody species. Mycorrhizal association represents arbuscular mycorrhizal (AM) and ectomycorrhizal (ECM) fungi. The sample size for each group is in parentheses. Error bars represent $95 \%$ confidence intervals (Cls) of weighted response ratio. If $95 \%$ Cls do not overlap with zero the rhizosphere effect is considered significant $(P<0.05$, denoted by solid points), otherwise is considered nonsignificant $\left(P>0.05\right.$, denoted by open points). $\mathrm{Q}_{\mathrm{B}}$ represents the heterogeneity in rhizosphere effect among groups, and the significant value of $\mathrm{Q}_{\mathrm{B}}$ indicates significant differences among groups $(P<0.05)$. 
effects on other soil variables (Table S4) or most properties of bulk soils (Table S5). The rhizosphere effect on soil gross $\mathrm{N}_{\text {min }}$ had significantly positive relationships with the rhizosphere effects on soil dissolved organic $C$ in non-woody species $\left(R^{2}=\right.$ $0.261, P=0.011$; Fig. $3 \mathrm{~A})$ and AM species $\left(R^{2}=0.219, P=\right.$ 0.033 ; Fig. $3 \mathrm{E}$ ). It was also positively correlated with the rhizosphere effects on microbial biomass $\mathrm{N}\left(R^{2}=0.124, P=\right.$ $0.038)$ and phenol oxidase activity $\left(R^{2}=0.252, P=0.048\right)$ across all species (Fig. 3A, 3B). Furthermore, the rhizosphere effect on soil gross $\mathrm{N}_{\min }$ significantly increased with the rhizosphere effect on soil $\mathrm{C}_{\min }\left(R^{2}=0.130, P=0.005\right.$; Fig. 3D). The positive relationships were consistent within each plant growth forms or AM species (Fig. 3D, 3H), but the regression slopes were different (woody>non-woody). The relationship between the rhizosphere effect on soil gross $\mathrm{N}_{\min }$ and root biomass was significantly positive $\left(R^{2}=0.117, P=\right.$ 0.017), but not for shoot biomass or total biomass (Fig. 4). Moreover, for climatic factors, the rhizosphere effect on soil gross $\mathrm{N}_{\min }$ had no significant correlation with MAT and MAP within and across different experimental types (Fig. S3).

Results from the weighted random forest analysis showed that the model explained $54 \%$ of the variations for the rhizosphere effect on soil gross $N_{\text {min }}$ (Fig. 5). Among the multiple variables, the significantly important moderates were the rhizosphere effect on soil $C_{\min }(20 \%$ IncMSE, $P<0.001)$, phenol oxidase activity $(13 \%$ IncMSE, $P<0.001)$ and root biomass $(14 \%$ IncMSE, $P<0.01)$. Relatively, other variables such as climatic factors, plant growth forms and mycorrhizal associations were of minor importance.

\section{Discussion}

Based on 24 published studies, this meta-analysis provided a comprehensive synthesis of the rhizosphere effect on soil gross $\mathrm{N}_{\min }$ overall and across different plant growth forms (woody and non-woody) and mycorrhizal associations (AM and ECM). Consistent with previous studies, our results demonstrated that the rhizosphere effect on soil gross $\mathrm{N}_{\text {min }}$ was significantly positive. It significantly varied among plant growth forms and mycorrhizal associations, but not among experimental settings (pot vs. field) and rhizosphere soil sampling methods (shaking vs. others). In addition, we highlighted the positive relationship between the rhizosphere effect on soil gross $\mathrm{N}_{\min }$ and the rhizosphere effect on soil $\mathrm{C}_{\min }$ within and across different types of plant growth forms. The rhizosphere effects on oxidative enzyme (phenol oxidase) activity, $\mathrm{C}_{\min }$ and root biomass were also important moderators affecting the variations in the rhizosphere effect on soil gross $\mathrm{N}_{\text {min }}$. Taken together, these novel findings reveal the changes and drivers in soil gross $\mathrm{N}_{\min }$ affected by rhizosphere processes, and improve our mechanistic understanding of soil nitrogen transformations in the rhizosphere.

\subsection{Patterns of the rhizosphere effect on soil gross $\mathrm{N}_{\min }$}

In the presence of living roots, soil $\mathrm{C}$ decomposition and net $\mathrm{N}$ mineralization were often accelerated (Cheng and Kuzyakov, 2005; Finzi et al., 2015), while existing research focused much
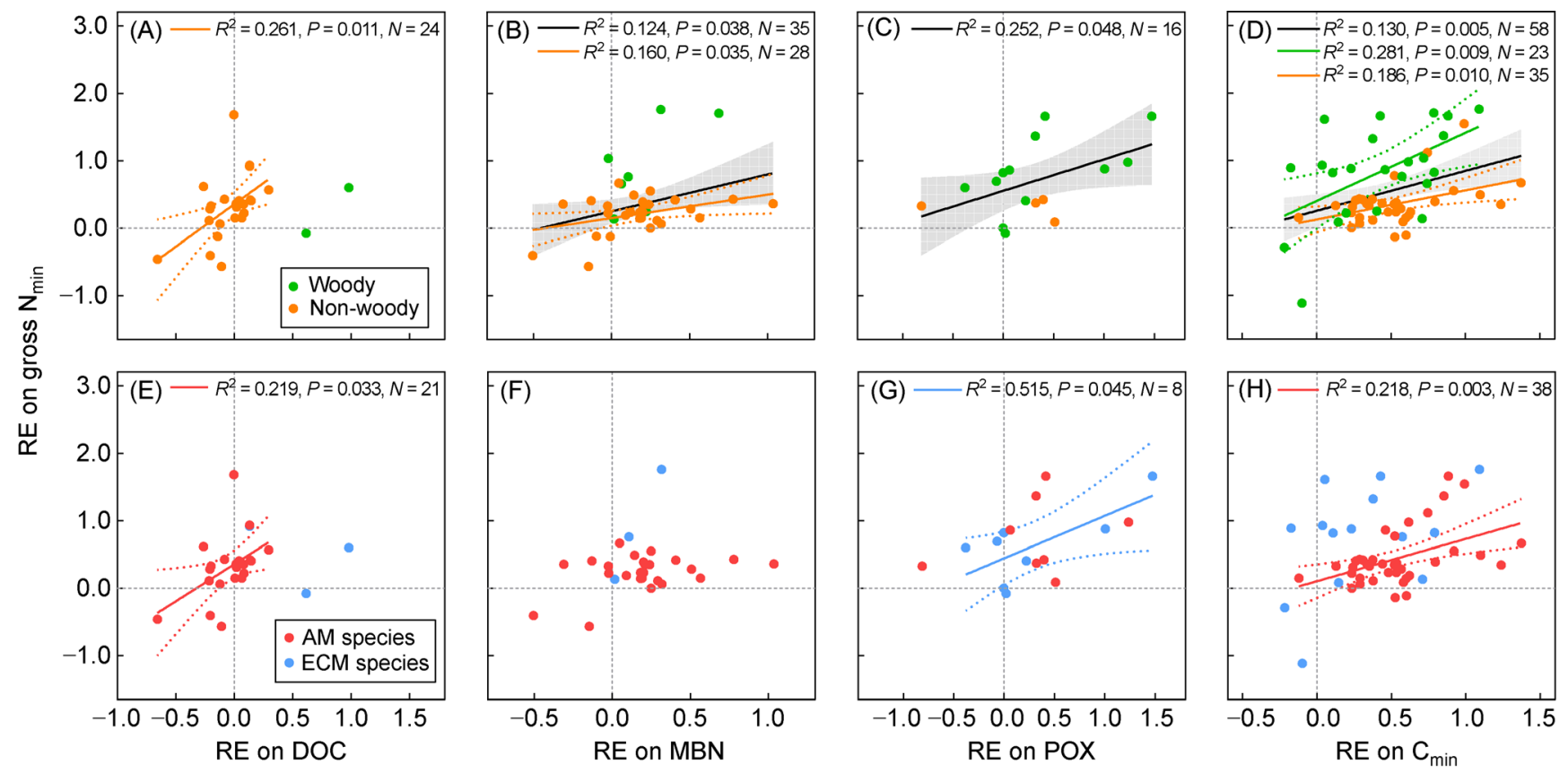

Fig. 3 Relationships of the rhizosphere effect $(R E)$ on soil gross nitrogen mineralization rate (gross $N_{\min }$ ) with the rhizosphere effect on soil dissolved organic carbon (DOC), microbial biomass nitrogen (MBC), phenol oxidase (POX) and carbon mineralization rate $\left(C_{\text {min }}\right)$ across and within plant growth forms and mycorrhizal types. The RE is calculated as the natural log-transformed response ratio of rhizosphere to bulk soil. Grey area represents $95 \%$ confidence intervals and only significant relations $(P<0.05)$ are drawn with regression lines. 

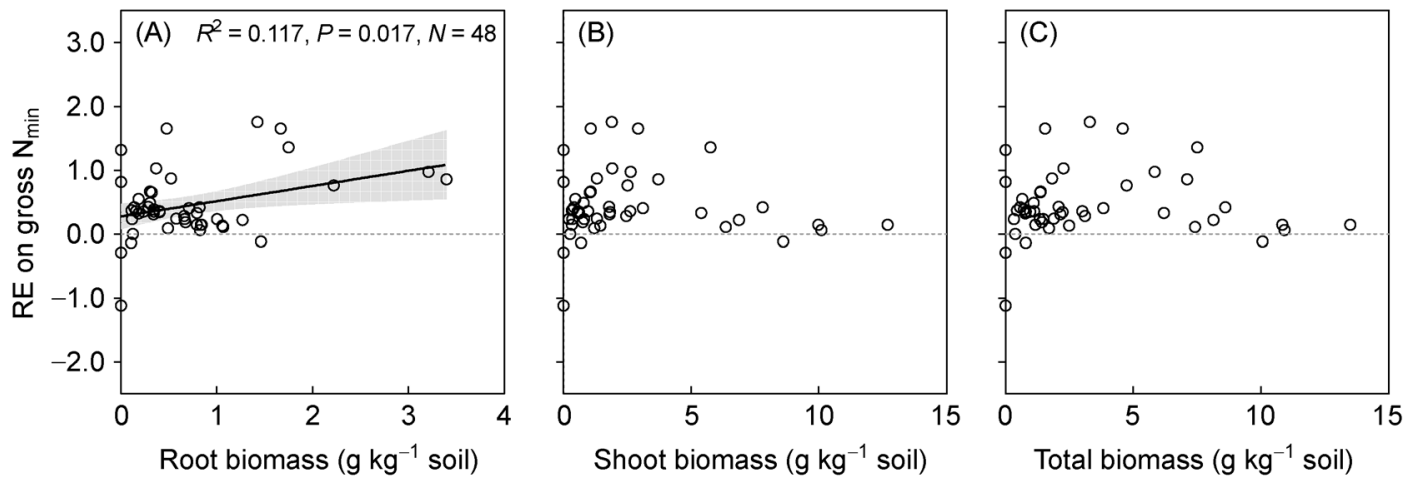

Fig. 4 Relationships of the rhizosphere effect (RE) on soil gross nitrogen mineralization rate (gross $\mathrm{N}_{\min }$ ) with plant biomass (root, shoot and total). The $\mathrm{RE}$ is calculated as the natural log-transformed response ratio of rhizosphere to bulk soil. Grey area represents $95 \%$ confidence intervals and only significant relations $(P<0.05)$ are drawn with regression lines.

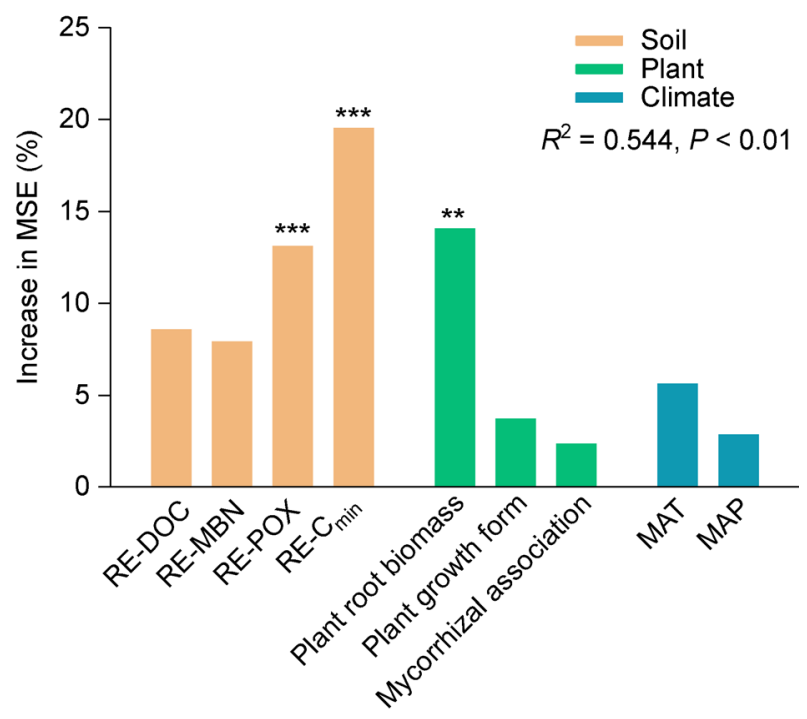

Fig. 5 Variable importance of moderators for the rhizosphere effects $(R E)$ on soil gross mineralization rate (gross $\mathrm{N}_{\min }$ ). Importance values are derived from a weighted random-forest analysis including variables as moderators. Percentage increases in the MSE (mean squared error) of variables were used to evaluate the importance of these predictors. DOC, soil dissolved organic carbon; MBN, microbial biomass nitrogen; POX, phenol oxidase; $\mathrm{C}_{\min }$, soil carbon mineralization rate; Plant growth form (woody and non-woody); Mycorrhizal association (arbuscular mycorrhizal, ectomycorrhizal); MAT, mean annual temperature; MAP, mean annual precipitation. Significance levels are as follows: ${ }^{\star} P<0.05,{ }^{\star \star} P<0.01$ and ${ }^{* \star} P<0.001$.

less on soil gross $\mathrm{N}_{\min }$ in the rhizosphere. Our meta-analysis showed that the rhizosphere effect on soil gross $N_{\text {min }}$ was significantly positive, with an increase of $81 \%$ on average compared to bulk soil ( $n=74$; Fig. 2). These results were consistent with our first hypothesis that rhizosphere effects tend to accelerate soil biogeochemical processes (particularly gross $\mathrm{N}$ mineralization). In comparison, the rhizosphere effect on soil gross $\mathrm{N}_{\min }$ in this study was lower than the result $(102 \%, n=11)$ in a previous work (Finzi et al., 2015). Such difference might be partly caused by the enlarged sample size of our database (74 vs. 11). Among the $\mathrm{C}$ and $\mathrm{N}$ cycling variables associated with soil gross $N_{\text {min }}$, microbial biomass (especially MBN) and enzyme activities (especially $\beta-1,4-N-$ acetyl-glucosaminidase) tended to show positive rhizosphere effects (Fig. 2A). This result indicated that microbial growth and enzyme activities were stimulated by rhizosphere processes to release mineral $\mathrm{N}$ from SOM, which supports the 'microbial activation' hypothesis (Kuzyakov, 2002; Cheng and Kuzyakov, 2005; Kuzyakov, 2010). Specifically, the plant releases labile $\mathrm{C}$ substrates to the rhizosphere through root exudates and litter, stimulating the rhizosphere-associated microbial growth (Dijkstra and Cheng, 2007). In this case, microbes could produce more extracellular enzymes to access soil available $\mathrm{N}$ by increasing $\mathrm{N}$ mineralization rate (Schimel and Bennett, 2004). Thus, the $\mathrm{N}$ mineralization rate was higher in the rhizosphere soil compared to the bulk soil, especially in N-limiting conditions (Zhu and Cheng, 2012; Blaško et al., 2013). Moreover, many studies have reported that the $\mathrm{C}$ mineralization rate was stimulated in the rhizosphere and the rhizosphere effect on $\mathrm{C}_{\min }$ tended to be positive (Kuzyakov, 2002; Cheng and Kuzyakov, 2005; Cheng et al., 2014). Consistent with these studies, we found that the magnitude of rhizosphere effect on $\mathrm{C}_{\min }$ was $57 \%$ (Fig. 2A). These results demonstrate that the rhizosphere is a hotspot for SOM turnover, and root stimulation of organic matter turnover is an effective way to supply the needed nutrients of plants (Kuzyakov and Blagodatskaya, 2015).

Among plant growth forms, the rhizosphere effects on soil gross $\mathrm{N}_{\min }$ were all positive and the magnitude of such rhizosphere effects appeared significantly different from each other (Fig. 2B). Woody species tended to exhibit stronger rhizosphere effects than non-woody species. There were two possible explanations for this result. On one hand, there were significant differences in root morphology, physiology and nutrient requirements among plant life forms (Jones et al., 2004), which may lead to species-specific rhizosphere effects on nutrient cycling (Kuzyakov, 2002). On the other hand, woody species roots were mostly associated with ECM, while non-woody species roots were associated with AM in our data 
set. Generally, ECM species would generate greater rhizosphere effects on soil gross $\mathrm{N}_{\min }$ than $\mathrm{AM}$ species (Fig. 2B), thus the stronger rhizosphere effects occurred in woody species may be partly caused by the mycorrhizal association of woody plants (predominantly ECM) in this study. Furthermore, our results showed that the rhizosphere effect on soil gross $\mathrm{N}_{\text {min }}$ positively correlated to the rhizosphere effect on $\mathrm{C}_{\text {min }}$ for all plant growth forms (Fig. 3D), suggesting the strong coupling between soil $\mathrm{C}$ and gross $\mathrm{N}$ mineralization in the rhizosphere (Dijkstra et al., 2009; Zhu et al., 2014).

Plant mycorrhizal associations (particularly AM vs. ECM) have been proposed to affect belowground resource-acquisition strategies (Bergmann et al., 2020; Han and Zhu, 2021), and the different turnover rates of fungal hyphae could influence the magnitude of rhizosphere effects (Phillips and Fahey, 2006). However, the underlying mechanisms of mycorrhizal effects on rhizosphere processes remain elusive (Lin et al., 2017). Our results showed that the rhizosphere effect on soil gross $\mathrm{N}_{\min }$ was significantly higher under ECM species than under AM species. This difference was also observed in the same plant growth form (woody species) but with different mycorrhizal associations (AM trees vs. ECM trees, Fig. 2B). Earlier studies found that ECM tree species generated greater rhizosphere effects than $A M$ tree species due to their higher root exudation rates and different microbial community composition (Phillips and Fahey, 2006; Yin et al., 2014; Brzostek et al., 2015). Furthermore, the rhizosphere effect on soil gross $\mathrm{N}_{\min }$ positively correlated with the rhizosphere effect on soil phenol oxidase activity in ECM species, but not in AM species (Fig. 4C). Likely, ECM roots had stronger abilities to release oxidative enzymes (Frank and Groffman, 2009; Lindahl and Tunlid, 2015), thereby leading to the greater rhizosphere effect on soil gross $N_{\min }$ in ECM species compared to that in AM species.

4.2 Potential influencing factors for the rhizosphere effect on soil gross $\mathrm{N}_{\min }$

There are many factors potentially affecting the rhizosphere effect, including biotic and abiotic factors (Kuzyakov, 2010; Cheng et al., 2014; Sun et al., 2014). Here we focused on soil biogeochemical variables, plant traits and climatic factors for the rhizosphere effect on soil gross $\mathrm{N}_{\min }$. For soil properties, our results showed that the rhizosphere effect on soil dissolved organic $\mathrm{C}$ significantly and positively correlated with the rhizosphere effect on soil gross $\mathrm{N}_{\min }$ in non-woody species (Fig. 3A, Table S3), suggesting that DOC as substrate for microbial growth could facilitate microbial $\mathrm{N}$ mineralization. Moreover, the rhizosphere effect on soil gross $\mathrm{N}_{\text {min }}$ did not show significant correlations with inorganic $\mathrm{N}$ in the bulk soil (Table S5) or the rhizosphere effect on inorganic N (Table S4). These results seem to be inconsistent with the ' $\mathrm{N}$ mining' hypothesis (Craine et al., 2007; Fontaine et al., 2011; Dijkstra et al., 2013) which posits that the rhizosphere effect on soil gross $\mathrm{N}_{\min }$ would be stronger in more $\mathrm{N}$-limited soils.
However, this result should be interpreted with caution because 1) extractable inorganic $N$ may not be a good indicator of $\mathrm{N}$ availability among different soil types (Van Sundert et al., 2020), and 2) other co-varying factors may mask the relationship between soil $\mathrm{N}$ availability and the rhizosphere effect on soil gross $\mathrm{N}_{\min }$ (Dijkstra et al., 2013).

Moreover, we found positive relationships between the rhizosphere effect on soil gross $\mathrm{N}_{\min }$ and the rhizosphere effects on microbial variables such as microbial biomass $\mathrm{N}$ and phenol oxidase activity (Fig. 3B, 3C), indicating that rhizosphere microbes could regulate soil gross $\mathrm{N}_{\min }$ according to their nutrient demand. These results are consistent with the 'microbial $\mathrm{N}$ mining' hypothesis. The oxidative enzyme (phenol oxidase) was linked to the degradation of recalcitrant SOM and changes in its activity may have significant impact on soil N mineralization (Zhu et al., 2014; Meier et al., 2015). Moreover, consistent with our results, increasing case studies demonstrated that the positive rhizosphere priming of SOM decomposition would also enhance soil gross $\mathrm{N}_{\min }$, and the rhizosphere effect on SOM decomposition was proportional to that on soil gross $\mathrm{N}_{\min }$ (Zhu et al., 2014; Murphy et al., 2015; Yin et al., 2018; Jiang et al., 2021; Mo et al., 2021). In addition, climatic factors (MAT and MAP) might indirectly control the rhizosphere effect on soil gross $\mathrm{N}_{\text {min }}$. However, the rhizosphere effect on soil gross $N_{\min }$ exhibited not significant relationships with MAT and MAP (Fig. S3), and MAT and MAP were not strong moderators of the rhizosphere effect on soil gross $\mathrm{N}_{\min }$ when considering other factors such as soil and plant characteristics in the full random forest model (Fig. 5). These results suggest that climate is less important than soil microbial variables (e.g., $\mathrm{C}_{\min }$ and oxidase) in explaining the large-scale variations of the rhizosphere effect on soil gross $\mathrm{N}_{\text {min }}$. Given the relatively small coverage of climate and region in this study (Fig. S1), the role of climate on the spatial variation of rhizosphere effect on soil gross $\mathrm{N}_{\min }$ awaits further study with more data from less-sampled regions.

Plant root traits are closely linked to rhizosphere processes, and hence may influence soil belowground processes (Bardgett et al., 2014). Our results showed that the rhizosphere effect on gross $\mathrm{N}_{\text {min }}$ had significant correlations with plant root biomass, while the correlations with plant shoot biomass and total biomass were not significant (Fig. 4). Similarly, previous studies found the RPE was positively correlated with root biomass. (Fu and Cheng, 2002; Dijkstra et al., 2006; Yin et al., 2018). These findings suggest that the rhizodeposition and root biomass could control rhizosphere effects on soil $\mathrm{C}$ and $\mathrm{N}$ mineralization.

Collectively, the regulation of different moderators for the rhizosphere effect on soil gross $\mathrm{N}_{\text {min }}$ was assessed by a random forest model. Consistent with our second hypothesis, the rhizosphere effects on $\mathrm{C}_{\mathrm{min}}$, phenol oxidase and root biomass were the three most important regulators of the rhizosphere effect on soil gross $N_{\text {min }}$ (Fig. 5). This result suggested the dominant role of soil microbes in influencing soil gross $\mathrm{N}_{\min }$ and the coupled relationships between $\mathrm{C}$ and gross N mineralization (Hart et al., 1994; Booth et al., 2005). 
The rhizosphere effect on oxidative enzymes was more important to the rhizosphere effect on soil gross $\mathrm{N}_{\min }$, compared to the rhizosphere effect on hydrolytic enzymes, which supports earlier studies (Zhu et al., 2014; Yin et al., 2018). Moreover, our results showed that root biomass also significantly correlated with the rhizosphere effect on soil gross $\mathrm{N}_{\min }$ in the model. There were significant differences in the rhizosphere effect on soil gross $\mathrm{N}_{\min }$ among plant growth forms and mycorrhizal associations. But compared to soil microbial factors, these plant factors and climatic factors were poor predictors and appeared less important. It should be noted that recent studies reported that plant species with different economic strategies could regulate soil $\mathrm{C}$ and $\mathrm{N}$ cycling through their rhizosphere effects (Han et al., 2020a; Henneron et al., 2020), providing evidence that plant traits other than growth forms and mycorrhizal associations should be paid attention to in future studies on rhizosphere effects.

\section{Conclusions}

Our meta-analysis quantitatively assessed the patterns of the rhizosphere effect on soil gross $\mathrm{N}_{\min }$ and compared their differences among plant growth forms and mycorrhizal associations. These results highlight that the rhizosphere process can accelerate soil gross $\mathrm{N}$ mineralization rate and related microbial variables (biomass and enzyme), indicating that rhizosphere effects play important roles in driving belowground biogeochemical processes. The rhizosphere effect on soil gross $\mathrm{N}_{\min }$ was $81 \%$ on average, and it differed greatly among plant growth forms (woody>non-woody) and mycorrhizal associations (ECM>AM). The rhizosphere effect on soil gross $\mathrm{N}_{\text {min }}$ significantly correlated with the rhizosphere effect on soil microbial biomass nitrogen and plant root biomass. Specifically, the rhizosphere effect on soil gross $N_{\min }$ was mainly influenced by the rhizosphere effects on phenol oxidase and $\mathrm{C}_{\min }$ rather than by other plant (growth form and mycorrhizal association) and climatic (MAT and MAP) factors. However, as soil $\mathrm{N}$ mineralization and immobilization occur simultaneously, further studies should consider multiple $\mathrm{N}$ transformation processes comprehensively in the rhizosphere (Frank and Groffman, 2009). Moreover, further studies should explore the relative roles of plant functional traits (including leaf, fungal and root traits), soil physico-chemical and microbial properties, and environmental conditions in influencing the variations of rhizosphere effects. Taken together, these results could enrich our understanding of how rhizosphere effects regulate belowground $\mathrm{C}$ and $\mathrm{N}$ cycling in terrestrial ecosystems on a large scale, and also contribute to development of ecosystem models that consider plant-microbe interactions in the rhizosphere.

\section{Acknowledgments}

This study was supported by the National Natural Science Foundation of China (31971528 and 31988102). We sincerely thank all the scientists whose data and work were included in this meta-analysis. BZ conceived and designed the study. DYG extracted the data from the literature and conducted the data analysis. DYG and BZ wrote the first draft of the paper. All authors critically commented on the draft and provided interpretation.

\section{Electronic supplementary material}

Supplementary material is available in the online version of this article at https://doi.org/10.1007/s42832-021-0098-y and is accessible for authorized users.

\section{References}

Bai, E., Li, S.L., Xu, W.H., Li, W., Dai, W.W., Jiang, P., 2013. A metaanalysis of experimental warming effects on terrestrial nitrogen pools and dynamics. New Phytologist 199, 441-451.

Bardgett, R.D., Mommer, L., De Vries, F.T., 2014. Going underground: root traits as drivers of ecosystem processes. Trends in Ecology \& Evolution 29, 692-699.

Bergmann, J., Weigelt, A., van der Plas, F., Laughlin, D.C., Kuyper, T. W., Guerrero-Ramirez, N., Valverde-Barrantes, O.J., Bruelheide, H., Freschet, G.T., Iversen, C.M., Kattge, J., McCormack, M.L., Meier, I.C., Rillig, M.C., Roumet, C., Semchenko, M., Sweeney, C. J., van Ruijven, J., York, L.M., Mommer, L., 2020. The fungal collaboration gradient dominates the root economics space in plants. Science Advances 6, eaba3756.

Blaško, R., Högberg, P., Bach, L., Högberg, M., 2013. Relations among soil microbial community composition, nitrogen turnover, and tree growth in $\mathrm{N}$-loaded and previously $\mathrm{N}$-loaded boreal spruce forest. Forest Ecology and Management 302, 319-328.

Booth, M., Stark, J., Rastetter, E., 2005. Controls on nitrogen cycling in terrestrial ecosystems: A synthetic analysis of literature data. Ecological Monographs 75, 139-157.

Brzostek, E.R., Dragoni, D., Brown, Z.A., Phillips, R.P., 2015. Mycorrhizal type determines the magnitude and direction of rootinduced changes in decomposition in a temperate forest. New Phytologist 206, 1274-1282.

Brzostek, E.R., Greco, A., Drake, J.E., Finzi, A.C., 2013. Root carbon inputs to the rhizosphere stimulate extracellular enzyme activity and increase nitrogen availability in temperate forest soils. Biogeochemistry 115, 65-76.

Chen, J., Luo, Y.Q., van Groenigen, K.J., Hungate, B.A., Cao, J.J., Zhou, X.H., Wang, R.W., 2018a. A keystone microbial enzyme for nitrogen control of soil carbon storage. Science Advances 4, eaaq1689.

Chen, X., Ding, Z.J., Tang, M., Zhu, B., 2018b. Greater variations of rhizosphere effects within mycorrhizal group than between mycorrhizal group in a temperate forest. Soil Biology \& Biochemistry $126,237-246$.

Cheng, W.X., 1999. Rhizosphere feedback in elevated $\mathrm{CO}_{2}$. Tree Physiology 19, 313-320.

Cheng, W.X., Johnson, D.W., Fu, S.L., 2003. Rhizosphere effects on decomposition: Controls of plant species, phenology, and fertilization. Soil Science Society of America Journal 67, 1418-1427.

Cheng, W.X., Kuzyakov, Y., 2005. Root Effects on Soil Organic Matter 
Decomposition. In: Zobel, R.W., Wright, S.F., eds. Roots and Soil Management: Interactions between Roots and the Soil, Agronomy Monograph No. 48. ASA-CSSA-SSSA, Madison, WI, pp. 119-143.

Cheng, W.X., Parton, W.J., Gonzalez-Meler, M.A., Phillips, R., Asao, S., McNickle, G.G., Brzostek, E., Jastrow, J.D., 2014. Synthesis and modeling perspectives of rhizosphere priming. New Phytologist 201, 31-44.

Colin-Belgrand, M., Dambrine, E., Bienaimé, S., Nys, C., Turpault, M. P., 2003. Influence of tree roots on nitrogen mineralization. Scandinavian Journal of Forest Research 18, 260-268.

Craine, J.M., Morrow, C., Fierer, N., 2007. Microbial nitrogen limitation increases decomposition. Ecology 88, 2105-2113.

Dieleman, W.I.J., Janssens, I.A., 2011. Can publication bias affect ecological research? A case study on soil respiration under elevated $\mathrm{CO}_{2}$. New Phytologist 190, 517-521.

Dijkstra, F.A., Bader, N.E., Johnson, D.W., Cheng, W.X., 2009. Does accelerated soil organic matter decomposition in the presence of plants increase plant $\mathrm{N}$ availability? Soil Biology \& Biochemistry 41, 1080-1087.

Dijkstra, F.A., Carrillo, Y., Pendall, E., Morgan, J.A., 2013. Rhizosphere priming: a nutrient perspective. Frontiers in Microbiology 4, 216.

Dijkstra, F.A., Cheng, W.X., 2007. Moisture modulates rhizosphere effects on $\mathrm{C}$ decomposition in two different soil types. Soil Biology \& Biochemistry 39, 2264-2274.

Dijkstra, F.A., Cheng, W.X., Johnson, D.W., 2006. Plant biomass influences rhizosphere priming effects on soil organic matter decomposition in two differently managed soils. Soil Biology \& Biochemistry 38, 2519-2526.

Dijkstra, F.A., Zhu, B., Cheng, W.X., 2021. Root effects on soil organic carbon: a double-edged sword. New Phytologist 230, 60-65.

Ding, Z.J., Tang, M., Cheng, W.X., Chen, X., Yin, L.M., Gui, H.C., Zhu, B., 2019. Measuring rhizosphere effects of two tree species in a temperate forest: A comprehensive method comparison. Rhizosphere 10, 100153.

Feng, J.G., Zhu, B., 2019. A global meta-analysis of soil respiration and its components in response to phosphorus addition. Soil Biology \& Biochemistry 135, 38-47.

Feng, J.G., Zhu, B., 2021. Global patterns and associated drivers of priming effect in response to nutrient addition. Soil Biology \& Biochemistry 153, 108118.

Finzi, A.C., Abramoff, R.Z., Spiller, K.S., Brzostek, E.R., Darby, B.A., Kramer, M.A., Phillips, R.P., 2015. Rhizosphere processes are quantitatively important components of terrestrial carbon and nutrient cycles. Global Change Biology 21, 2082-2094.

Fontaine, S., Henault, C., Aamor, A., Bdioui, N., Bloor, J., Maire, V., Mary, B., Revaillot, S., Maron, P., 2011. Fungi mediate long term sequestration of carbon and nitrogen in soil through their priming effect. Soil Biology \& Biochemistry 43, 86-96.

Frank, D.A., Groffman, P.M., 2009. Plant rhizospheric N processes: what we don't know and why we should care. Ecology 90, 15121519.

Fu, S.L., Cheng, W.X., 2002. Rhizosphere priming effects on the decomposition of soil organic matter in $\mathrm{C}_{4}$ and $\mathrm{C}_{3}$ grassland soils. Plant and Soil 238, 289-294.

Hamer, U., Makeschin, F., 2009. Rhizosphere soil microbial commu- nity structure and microbial activity in set-aside and intensively managed arable land. Plant and Soil 316, 57-69.

Han, M.G., Sun, L.J., Gan, D.Y., Fu, L.C., Zhu, B., 2020a. Root functional traits are key determinants of the rhizosphere effect on soil organic matter decomposition across 14 temperate hardwood species. Soil Biology \& Biochemistry 151, 108019.

Han, M.G., Zhu, B., 2021. Linking root respiration to chemistry and morphology across species. Global Change Biology 27, 190-201.

Han, Y.F., Feng, J.G., Han, M.G., Zhu, B., 2020b. Responses of arbuscular mycorrhizal fungi to nitrogen addition: A meta-analysis. Global Change Biology 26, 7229-7241.

Hart, S.C., Nason, G.E., Myrold, D.D., Perry, D.A., 1994. Dynamics of gross nitrogen transformations in an old-growth forest: The carbon connection. Ecology 75, 880-891.

Hedges, L.V., Gurevitch, J., Curtis, P.S., 1999. The meta-analysis of response ratios in experimental ecology. Ecology 80, 11501156.

Henneron, L., Kardol, P., Wardle, D., Camille, C., Fontaine, S., 2020. Rhizosphere control of soil nitrogen cycling: a key component of plant economic strategies. New Phytologist 228, 1269-1282.

Herman, D.J., Johnson, K.K., Jaeger, C.H., Schwartz, E., Firestone, M.K., 2006. Root influence on nitrogen mineralization and nitrification in Avena barbata rhizosphere soil. Soil Science Society of America Journal 70, 60-66.

Hobbie, S., 1992. Effect of plant species on nutrient cycling. Trends in Ecology \& Evolution 7, 336-339.

Holz, M., Aurangojeb, M., Kasimir, Å., Boeckx, P., Kuzyakov, Y., Klemedtsson, L., Rütting, T., 2016. Gross nitrogen dynamics in the mycorrhizosphere of an organic forest soil. Ecosystems (New York, N.Y.) 19, 284-295.

Huo, C.F., Luo, Y.Q., Cheng, W.X., 2017. Rhizosphere priming effect: A meta-analysis. Soil Biology \& Biochemistry 111, 78-84.

Jiang, Z.H., Liu, Y.Z., Yang, J.P., Brookes, P.C., Gunina, A., 2021. Rhizosphere priming regulates soil organic carbon and nitrogen mineralization: The significance of abiotic mechanisms. Geoderma 385, 114877.

Jiao, S., Chen, W.M., Wang, J., Du, N.N., Li, Q.P., Wei, G.H., 2018. Soil microbiomes with distinct assemblies through vertical soil profiles drive the cycling of multiple nutrients in reforested ecosystems. Microbiome 6, 146.

Jones, D.L., Hodge, A., Kuzyakov, Y., 2004. Plant and mycorrhizal regulation of rhizodeposition. New Phytologist 163, 459-480.

Keller, A.B., Phillips, R.P., 2019. Leaf litter decay rates differ between mycorrhizal groups in temperate, but not tropical, forests. New Phytologist 222, 556-564.

Koranda, M., Schnecker, J., Kaiser, C., Fuchslueger, L., Kitzler, B., Stange, C.F., Sessitsch, A., Zechmeister-Boltenstern, S., Richter, A., 2011. Microbial processes and community composition in the rhizosphere of European beech-The influence of plant $\mathrm{C}$ exudates. Soil Biology \& Biochemistry 43, 551-558.

Kuzyakov, Y., 2002. Review: Factors affecting rhizosphere priming effects. Journal of Plant Nutrition and Soil Science 165, 382-396.

Kuzyakov, Y., 2010. Priming effects: interactions between living and dead organic matter. Soil Biology \& Biochemistry 42, 1363-1371.

Kuzyakov, Y., Blagodatskaya, E., 2015. Microbial hotspots and hot moments in soil: Concept \& review. Soil Biology \& Biochemistry 83, 
184-199.

Kuzyakov, Y., Xu, X.L., 2013. Competition between roots and microorganisms for nitrogen: mechanisms and ecological relevance. New Phytologist 198, 656-669.

Lebauer, D., Treseder, K., 2008. Nitrogen limitation of net primary productivity in terrestrial ecosystems is globally distributed. Ecology 89, 371-379.

Li, X.W., Zhang, C.L., Zhang, B.B., Wu, D., Zhu, D.D., Zhang, W., Ye, Q., Yan, J.H., Fu, J.M., Fang, C.L., Ha, D.L., Fu, S.L., 2021. Nitrogen deposition and increased precipitation interact to affect fine root production and biomass in a temperate forest: Implications for carbon cycling. Science of the Total Environment 765 , 144497.

Liao, C.Z., Peng, R.H., Luo, Y.Q., Zhou, X.H., Wu, X.W., Fang, C.M., Chen, J.K., Li, B., 2008. Altered ecosystem carbon and nitrogen cycles by plant invasion: a meta-analysis. New Phytologist 177 , 706-714.

Lin, G.G., Guo, D.L., Li, L., Ma, C.E., Zeng, D.H., 2017. Contrasting effects of ectomycorrhizal and arbuscular mycorrhizal tropical tree species on soil nitrogen cycling: the potential mechanisms and corresponding adaptive strategies. Oikos 127, 518-530.

Lindahl, B.D., Tunlid, A., 2015. Ectomycorrhizal fungi - potential organic matter decomposers, yet not saprotrophs. New Phytologist 205, 1443-1447.

Liu, L.L., Wang, X., Lajeunesse, M.J., Miao, G.F., Piao, S.L., Wan, S. Q., Wu, Y.X., Wang, Z.H., Yang, S., Li, P., Deng, M.F., 2016. A cross-biome synthesis of soil respiration and its determinants under simulated precipitation changes. Global Change Biology 22 , 1394-1405.

Luo, Y.Q., Zhang, D.Q., Hui, D.F., 2006. Elevated $\mathrm{CO}_{2}$ stimulates net accumulations of carbon and nitrogen in land ecosystems: a metaanalysis. Ecology 87, 53-63.

Maire, V., Wright, I., Prentice, I., Batjes, N., Bhaskar, R., Bodegom, P., Cornwell, W., Ellsworth, D., Niinemets, Ü., Ordonez, A., Reich, P., Santiago, L., 2015. Global effects of soil and climate on leaf photosynthetic traits and rates: Effects of soil and climate on photosynthetic traits. Global Ecology and Biogeography 24, 706717.

Meier, I., Pritchard, S., Brzostek, E., McCormack, M., Phillips, R., 2015. The rhizosphere and hyphosphere differ in their impacts on carbon and nitrogen cycling in forests exposed to elevated $\mathrm{CO}_{2}$. New Phytologist 205, 1164-1174.

Mo, C.Y., Jiang, Z.H., Chen, P.F., Cui, H., Yang, J.P., 2021. Microbial metabolic efficiency functions as a mediator to regulate rhizosphere priming effects. Science of the Total Environment 759 , 143488.

Murphy, C.J., Baggs, E.M., Morley, N., Wall, D.P., Paterson, E., 2015. Rhizosphere priming can promote mobilisation of N-rich compounds from soil organic matter. Soil Biology \& Biochemistry 81 , 236-243.

Murphy, D.V., Recous, S., Stockdale, E.A., Fillery, I.R.P., Jensen, L., Hatch, D.J., Goulding, K.W.T., 2003. Gross nitrogen fluxes in soil: theory, measurement and application of ${ }^{15} \mathrm{~N}$ pool dilution techniques. Advances in Agronomy 79, 69-118.

Phillips, R.P., Fahey, T.J., 2006. Tree species and mycorrhizal associations influence the magnitude of rhizosphere effects.
Ecology 87, 1302-1313.

Pokharel, P., Qi, L., Chang, S.X., 2021. Manure-based biochar decreases heterotrophic respiration and increases gross nitrification rates in rhizosphere soil. Soil Biology \& Biochemistry 154, 108147.

Read, D.J., Perez-Moreno, J., 2003. Mycorrhizas and nutrient cycling in ecosystems - a journey towards relevance? New Phytologist 157, 475-492.

Schimel, J., Bennett, J., 2004. Nitrogen mineralization: challenges of a changing paradigm. Ecology 85, 591-602.

Soudzilovskaia, N., Vaessen, S., Barcelo, M., He, J., Rahimlou, S., Abarenkov, K., Brundrett, M., Gomes, S., Merckx, V., Tederesoo, L., 2020. FungalRoot: Global online database of plant mycorrhizal associations. New Phytologist 227, 955-966.

Sun, Y., Xu, X.L., Kuzyakov, Y., 2014. Mechanisms of rhizosphere priming effects and their ecological significance. Acta Phytoecologica Sinica 38, 62-75.

Sun, Y., Zang, H.D., Splettstößer, T., Kumar, A., Xu, X.L., Kuzyakov, Y., Pausch, J., 2021. Plant intraspecific competition and growth stage alter carbon and nitrogen mineralization in the rhizosphere. Plant, Cell \& Environment 44, 1231-1242.

Terrer, C., Jackson, R., Prentice, I., Keenan, T., Kaiser, C., Vicca, S., Fisher, J., Reich, P., Stocker, B., Hungate, B., Penuelas, J., McCallum, I., Soudzilovskaia, N., Cernusak, L., Talhelm, A., Van Sundert, K., Piao, S., Newton, P., Hovenden, M., Franklin, O., 2019. Nitrogen and phosphorus constrain the $\mathrm{CO}_{2}$ fertilization of global plant biomass. Nature Climate Change 9, 684-689.

Van Sundert, K., Radujković, D., Cools, N., De Vos, B., Etzold, S., Fernández-Martínez, M., Janssens, I.A., Merilä, P., Peñuelas, J., Sardans, J., Stendahl, J., Terrer, C., Vicca, S., 2020. Towards comparable assessment of the soil nutrient status across scales-Review and development of nutrient metrics. Global Change Biology 26, 392-409.

Viechtbauer, W., 2010. Conducting meta-analyses in $\mathrm{R}$ with the metafor package. Journal of Statistical Software 36, 1-48.

Wang, B., Qiu, Y.L., 2006. Phylogenetic distribution and evolution of mycorrhizas in land plants. Mycorrhiza 16, 299-363.

Weemstra, M., Mommer, L., Visser, E., Ruijven, J., Kuyper, T., Mohren, G.M.J., Sterck, F., 2016. Towards a multidimensional root trait framework: A tree root review. New Phytologist 211, 1159 1169.

Yin, H.J., Wheeler, E., Phillips, R.P., 2014. Root-induced changes in nutrient cycling in forests depend on exudation rates. Soil Biology \& Biochemistry 78, 213-221.

Yin, L.M., Dijkstra, F.A., Wang, P., Zhu, B., Cheng, W.X., 2018. Rhizosphere priming effects on soil carbon and nitrogen dynamics among tree species with and without intraspecific competition. New Phytologist 218, 1036-1048.

Zhu, B., Cheng, W.X., 2012. Nodulated soybean enhances rhizosphere priming effects on soil organic matter decomposition more than non-nodulated soybean. Soil Biology \& Biochemistry 51, 56 65.

Zhu, B., Gutknecht, J.L.M., Herman, D.J., Keck, D.C., Firestone, M.K., Cheng, W.X., 2014. Rhizosphere priming effects on soil carbon and nitrogen mineralization. Soil Biology \& Biochemistry 76, 183 192. 